Abstracted/indexed in Academic Search Complete, Asia Journals Online, Bangladesh Journals Online, Biological Abstracts, BIOSIS Previews, CAB

Abstracts, Current Abstracts, Directory of Open Access Journals, EMBASE/Excerpta Medica, Google Scholar, HINARI (WHO), International

Pharmaceutical Abstracts, Open J-gate, Science Citation Index Expanded, SCOPUS and Social Sciences Citation Index;

\title{
EGR1, EGFR and IGF1R protein expressions in non-small cell lung cancer and their clinical significances
}

\author{
Dujuan Yu' ${ }^{1}$, Ping Tan' ${ }^{1}$, Min Yu' ${ }^{2}$, Shaomin Shi' ${ }^{1}$ and Xue Wang3 \\ ${ }^{1}$ The Department of Respiration, China Japan Union Hospital of Jilin University, Changchun, Jilin, 130 033, China; \\ ${ }^{2}$ The Department of Cardiology, Affiliated Hospital of Beihua University, Jilin, Jilin, 1340 00, China; ${ }^{3}$ The \\ Center of Physical Examination, China Japan Union Hospital of Jilin University, Changchun, Jilin, 130 033, China.
}

\begin{tabular}{|l|}
\hline Article Info \\
\hline Received: $\quad$ 16 January 2016 \\
Accepted: $\quad$ 30 January 2016 \\
Available Online: $\quad 9$ March 2016 \\
DOI: 10.3329/bjp.v11iS1.26413 \\
\\
\\
Cite this article: \\
Yu D, Tan P, Yu M, Shi S, Wang X. \\
EGR1, EGFR and IGF1R protein ex- \\
pressions in non-small cell lung can- \\
cer and their clinical significances. \\
Bangladesh J Pharmacol. 2016; 11: \\
S123-S130.
\end{tabular}

\section{Abstract}

The purpose of this study was to investigate the incidence and clinical significance of alterations in EGFR, IGF1R and the cell signaling pathway activities induced by them, as well as EGR1 expression in resected non-small cell lung cancer (NSCLC). The protein expressions of biomarker were evaluated by Western blotting in tissues from 19 surgically resected NSCLCs. High expressions of EGR1, EGFR and IGF1R were detected in more than $30 \%$ tumor tissues. High expressions of pErk and pAkt were detected in more than $50 \%$ paracancer tissues. There were significant correlations between the NSCLC target factors detected $(p<0.05)$. Alterations of protein expressions of target factor detected in NSCLC were significantly associated with alterations in pathological subtype, differentiation, pathological stage, and smoking history. Positive EGR1 might be associated with good survival, while positive pErk might be associated with poor prognosis.

\section{Introduction}

EGFR and IGF1R play important roles in the tumorigenesis and development of lung cancers, and they have preferred therapeutic molecular targets. Through the ERK/MAPK and PI3K/AKT cell signaling pathways respectively, EGFR and IGF1R promote cell proliferation, drug resistance and metastasis of tumors (Mukohara et al., 1999; LeRoith and Roberts, 2003). EGR1 (early growth response gene 1) is a zinc finger transcription factor, subjecting to immediate early gene family, which regulates early cell growth. EGR1 overexpression is detected in the adenocarcinoma cells with K-RAS mutation-positive and EGFR mutation-positive (Ferraro et al., 2005). Recent study suggests that EGR1 is possibly a signaling crosstalk between the Erk pathway and Akt pathway. EGR1 may play a compen-

This paper was presented in the 3rd International Conference on Biomedicine and Pharmaceutics in Zhuhai, China, on December 11-13, 2015. satory role in the EGFR- or IGF1R-targeted therapy, by reducing drug resistance to the targeted drugs.

EGFR overexpression is reported to be correlated with poor survival (Hirsch et al., 2003). The relationship between IGF1R expression and prognosis is not determined (Nakagawa et al., 2012; Kim et al., 2014; Kim et al., 2012), and EGR1 expression seems to be a fine predictor in non-small cell lung cancer (NSCLC) patients (Ferraro et al., 2005).

The present study intends to investigate the activated state of both the EGFR and IGF1R signaling pathways in NSCLC, and the relationships among EGR1, EGFR, IGF1R and clinical data.

\section{Materials and Methods \\ Patients and specimens}

Patients included in the present study underwent surgi- 


\begin{tabular}{|c|c|c|c|c|c|}
\hline \multicolumn{6}{|c|}{ Table I } \\
\hline \multicolumn{6}{|c|}{ Patients' clinical and histopathological data } \\
\hline Clinical data & $\mathrm{n}$ & Clinical data & $\mathrm{n}$ & Clinical data & $\mathrm{n}$ \\
\hline Cases & 19 & Tumor status & & Perineurium infiltration & \\
\hline Mean age (60 years) & & $\mathrm{T} 1$ & 1 & Yes & 6 \\
\hline Gender & & $\mathrm{T} 2$ & 17 & No & 13 \\
\hline Male & 11 & $\mathrm{~T} 4$ & 1 & Pleura infiltration & \\
\hline Female & 8 & Nodal status & & Yes & 4 \\
\hline Smoking & & N0 & 7 & No & 5 \\
\hline Yes & 11 & N1 & 4 & Bronchus infiltration & \\
\hline No & 8 & N2 & 8 & Yes & 3 \\
\hline Pathology & & Pathological stage & & No & 6 \\
\hline Squamous cell carcinoma & 10 & I & 5 & Total survival & \\
\hline Adenocarcinoma & 9 & II & 5 & more than 4 years & 3 \\
\hline Differentiation & & III & 9 & 3-4 years & 8 \\
\hline Poor & 4 & Vascular infiltration & & 1-3 years & 7 \\
\hline \multirow[t]{2}{*}{ Moderate } & 15 & Yes & 14 & less than 1 year & 1 \\
\hline & & No & 5 & & \\
\hline
\end{tabular}

cal resections for NSCLC from 2010 to 2011 in China Japan Union Hospital of Jilin University. The patients' clinical and histopathological information was presented in Table I. No patients underwent antineoplastic therapy prior to surgery. Totally 38 resected tissue specimens were obtained from 19 patients. All the patients donated their primary lung squamous cell carcinoma (SCC) tissues (S1-S10), corresponding paracancer tissues (SP1-SP10), primary lung adenocarcinoma tissues (A1-A9) and the corresponding paracancer tissues (AP1-AP9). HE staining was obtained (Figure 1). All the patients gave the informed consent.

\section{Western blotting}

Cells were separated from tumor mass and paired

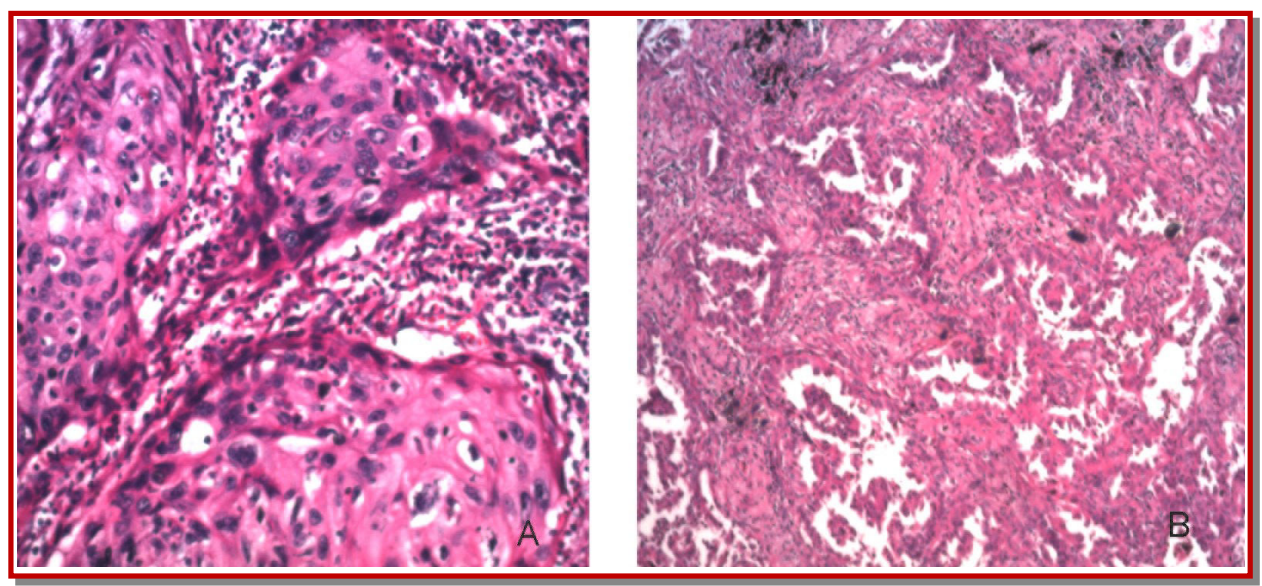

Figure 1: HE staining fo lung cancer

Note: A. Lung squamous cell carcinoma; B. Lung adenocarcinoma paracancer tissues, then lysed in the lysis buffer in the presence of protease and phosphatase inhibitors. The protein concentration was determined by the BCA method (Bio-Rad, USA). Proteins were separated on $15 \%$ gels by SDS-PAGE and transblot to PVDF membranes (Millipore, China). The membranes were incuba -ted in TBS-Tween 20 (TBST) containing 5\% BSA 2 hours at room temperature. Monoclonal primary antibodies against EGR1, EGFR, IGF1R $\beta$ subunit, pErk and pAkt were purchased from Santa Cruz Biotechnology Inc. (USA) and used by 1:1000 diluted. $\beta$-actin was the inner reference (Santa Cruz Bio.). Peroxidaseconjugated secondary antibodies against mouse IgG (Santa Cruz Bio.) were used to mark the blots. The enhanced chemiluminescence (ECL. Pierce Biotechno- 
Table II

Protein expression comparison between lung cancer tissues and para-cancers

\begin{tabular}{|l|c|c|rrr|}
\hline & \multicolumn{5}{c|}{ Blot grayscale ratio (/actin) of lung cancer factors } \\
\cline { 2 - 6 } & EGFR/ & IGF1R/ & EGR1/ & pErk/ & pAkt/ \\
Cancer tissues & 11.3 & 10.8 & 8.6 & 3.3 & 7.3 \\
Paracancers & 7.2 & 6.0 & 11.9 & 11.3 & 11.2 \\
$p$ value & $0.036^{\mathrm{a}}$ & $0.002^{\mathrm{a}}$ & 1.000 & $0.001^{\mathrm{a}}$ & $0.040^{\mathrm{a}}$ \\
\hline
\end{tabular}

Mann-Whitney U-test is used to analyze the relationships between the expression levels of biomarkers; ${ }^{a} p<0.05$ indicates a statistically significant difference

logy, Inc., USA) light system method was used for color development. Blots were scanned by a UVI Alliance 4.7 densitometer (Uvitec Inc., UK). The grayscale ratios of protein versus $\beta$-actin blots were quantified by UVI soft image quantification software (Uvitec Inc., UK).

\section{Statistical analysis}

The statistical software SPSS19.0 (SPSS, Inc., USA) was used for statistical analysis of the data. The MannWhitney U-test was used to analyze the relationships between the expression levels of biomarkers and clinic pathologic data. Spearman rank correlation coefficient was used to analyze the relationships among biomarker expression levels in tumor mass and/or paired paracancer tissues. Kaplain-Meier test with log-rank test was used to evaluate the NSCLC survival impacted by the overexpression of biomarkers EGR1, EGFR and IGF1R in tumor tissues, or the overexpression of pErk and pAkt in paracancer tissues. Statistical significance was set at $p<0.05$.

\section{Results}

\section{Western blotting analysis}

Overexpression of EGR1 protein was detected in 52.6\%
$(10 / 19)$ NSCLC tissues. Overexpression of EGFR protein was $36.8 \%(7 / 19)$ NSCLC tissues. Overexpression of IGF1R protein was $78.9 \%(15 / 19)$ NSCLC tissues. Overexpression of pErk protein was 63.2\% (12/19) paracancer tissues. Overexpression of pAkt protein was detected in 52.6\% (10/19) paracancer tissues (Figure 2).

\section{Protein expression comparison}

The difference for the expression of EGFR, IGF1R, pErk and pAkt between lung cancer tissues and paracancers were significant $(p<0.05)$, while the difference for EGR1 expression between these two tissues was not significant ( Table II).

Relationships among protein expressions of EGR1, EGFR, IGF1R, pErk, pAkt and clinical data in NSCLC patients

EGR1 protein expression was correlated with differentiation, pathological subtype and smoking history. EGFR protein expression was correlated with the pathological subtype, pathological stage and smoking history. IGF1R protein expression was correlated with the pathological subtype. pErk protein expression was correlated with differentiation, pathological subtype, pathological stage and smoking history. pAkt protein expression was correlated with differentiation, patholo-

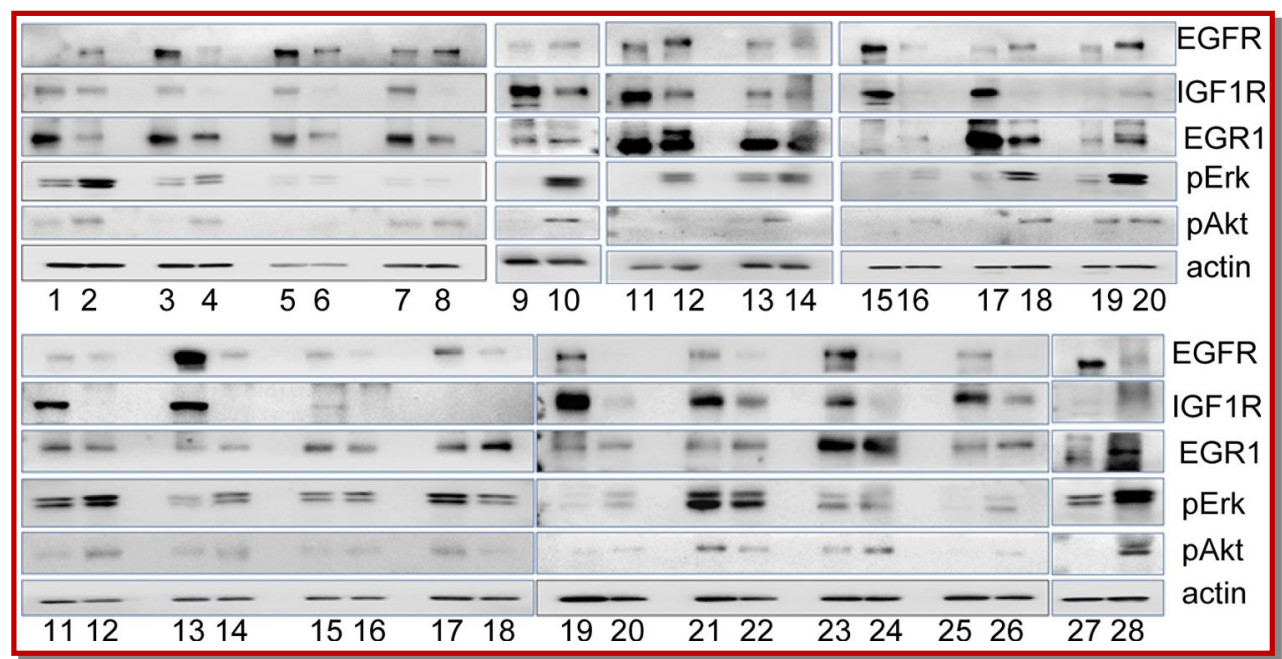

Figure 2: Westem blot analysis of lung cancer biomarkers in NSCLC tissues and paired paracancers

Note: Odd number lanes are cancer samples; even number lanes are paracancer samples 
Table III

\begin{tabular}{|c|c|c|c|c|c|c|c|}
\hline Clinical data & Cases (n) & EGFR/ & IGF1R/ & EGR1/ & ParacamerpErk/ & Paracancer pAkt/ & \\
\hline Gender & & $(0.152)$ & $(0.310)$ & $(0.152)$ & $(0.283)$ & $(0.069 \mathrm{a})$ & ( $\mathrm{p}$ value) \\
\hline Male & 11 & 8.3 & 8.8 & 8.4 & 8.8 & 8.0 & \\
\hline Female & 8 & 12.3 & 11.6 & 12.3 & 11.6 & 12.8 & \\
\hline Differentiation & & $(0.530)$ & $(0.460)$ & $(0.049 \mathrm{a})$ & $\left(0.046^{a}\right)$ & $\left(0.028^{a}\right)$ & ( $\mathrm{p}$ value) \\
\hline Poor & 4 & 8.3 & 8.0 & 5.0 & 5.0 & 4.5 & \\
\hline Moderate & 15 & 10.5 & 10.5 & 11.3 & 11.3 & 11.5 & \\
\hline Pathology type & & $(0.013 \mathrm{a})$ & $(0.043 \mathrm{a})$ & $\left(0.035^{\mathrm{a}}\right)$ & $\left(0.034^{a}\right)$ & $\left(0.001^{\mathrm{a}}\right)$ & ( $\mathrm{p}$ value) \\
\hline SCC & 10 & 7.0 & 7.5 & 7.4 & 7.4 & 6.0 & \\
\hline $\mathrm{AC}$ & 9 & 13.3 & 12.8 & 12.9 & 12.9 & 14.4 & \\
\hline Pathological stage & & $(0.018 \mathrm{a})$ & $(0.120)$ & $(0.135)$ & $\left(0.015^{\mathrm{a}}\right)$ & $\left(0.015^{\mathrm{a}}\right)$ & ( $\mathrm{p}$ value) \\
\hline I & 6 & 4.7 & 6.2 & 7.0 & 5.8 & 5.8 & \\
\hline II & 4 & 11.5 & 12.8 & 8.5 & 7.5 & 7.5 & \\
\hline III & 9 & 12.9 & 11.3 & 12.7 & 13.9 & 13.9 & \\
\hline Tumor status & & $(0.111)$ & $(0.333)$ & $(0.556)$ & $(0.500)$ & $(0.500)$ & ( $\mathrm{p}$ value) \\
\hline $\mathrm{T} 1$ & 1 & 1.00 & 3.0 & 5.0 & 6.0 & 6.0 & \\
\hline $\mathrm{T} 2$ & 17 & 10.00 & 9.9 & 9.8 & 9.7 & 9.7 & \\
\hline Nodal status & & $\left(0.086^{a}\right)$ & $(0.164)$ & $(0.253)$ & $\left(0.083^{a}\right)$ & $\left(0.083^{a}\right)$ & ( $\mathrm{p}$ value) \\
\hline N0 & 7 & 6.3 & 6.9 & 8.0 & 7.6 & 7.6 & \\
\hline N1 & 4 & 11.5 & 12.8 & 8.5 & 7.0 & 7.5 & \\
\hline $\mathrm{N} 2$ & 8 & 12.5 & 11.4 & 12.5 & 13.4 & 13.4 & \\
\hline Smoking & & $\left(0.006^{a}\right)$ & $(0.069 \mathrm{a})$ & $\left(0.005^{a}\right)$ & $\left(0.006^{a}\right)$ & $\left(0.001^{\mathrm{a}}\right)$ & ( $\mathrm{p}$ value) \\
\hline Yes & 11 & 7.0 & 8.0 & 6.9 & 7.0 & 6.3 & \\
\hline No & 8 & 14.1 & 12.8 & 14.3 & 14.1 & 15.1 & \\
\hline
\end{tabular}

Mann-Whitney U-test is used to analyze the relationships between the expression levels of lung cancer biomarkers and clinicopathologic data. ap< 0.05 indicates a statistically significant difference

Table IV

Correlation analysis of protein blot grayscale ratios $(\beta$-actin) in NSCLC

\begin{tabular}{|lcccc|} 
& Tumor IGF1R/ & Tumor EGR1/ & Paracancer pErk/ & Paracancer pAkt/ \\
\hline Tumor EGFR/ & $0.689\left(0.00^{*}\right)$ & $0.560\left(0.013^{\mathrm{a}}\right)$ & $0.665\left(0.002^{\mathrm{a}}\right)$ & $0.707\left(0.001^{\mathrm{a}}\right)$ \\
Tumor IGF1R/ & -- & $0.486\left(0.035^{\mathrm{a}}\right)$ & $0.649\left(0.003^{\mathrm{a}}\right)$ & $0.602\left(0.002^{\mathrm{a}}\right)$ \\
Tumor EGR1/ & -- & -- & $0.682\left(0.001^{\mathrm{a}}\right)$ & $0.735\left(0.000^{\mathrm{a}}\right)$ \\
Paracancer pErk/ & -- & -- & - & $0.844\left(0.000^{\mathrm{a}}\right)$ \\
\hline
\end{tabular}

Spearman rank correlation coefficient is used to analyze the relationships among lung cancer biomarkers' expression levels in tumor mass and/or paracancer tissues. Data are given as correlation coefficient ( $p$ value), and a $p<0.05$ indicates statistically significant difference

gical subtype, pathological stage and smoking history (Table III).

\section{Survival analysis of factors}

EGR1 protein expression was not associated with prognosis. Neither EGFR protein expression nor IGF1R protein expression was associated with overall survival. Not only pErk protein expression but also pAkt protein expression were associated with poor prognosis $(\mathrm{p}<0.05)$ (Figure 3).

\section{Correlation analysis of protein factors}

EGFR, IGF1R, EGR1, pErk and pAkt protien expressions were correlated with each other according to the analysis on the grayscale ratios (Table IV).

\section{Discussion}

In the present study, EGFR protein overexpression were detected in $30 \%$ NSCLC tissues. In NSCLC, the 

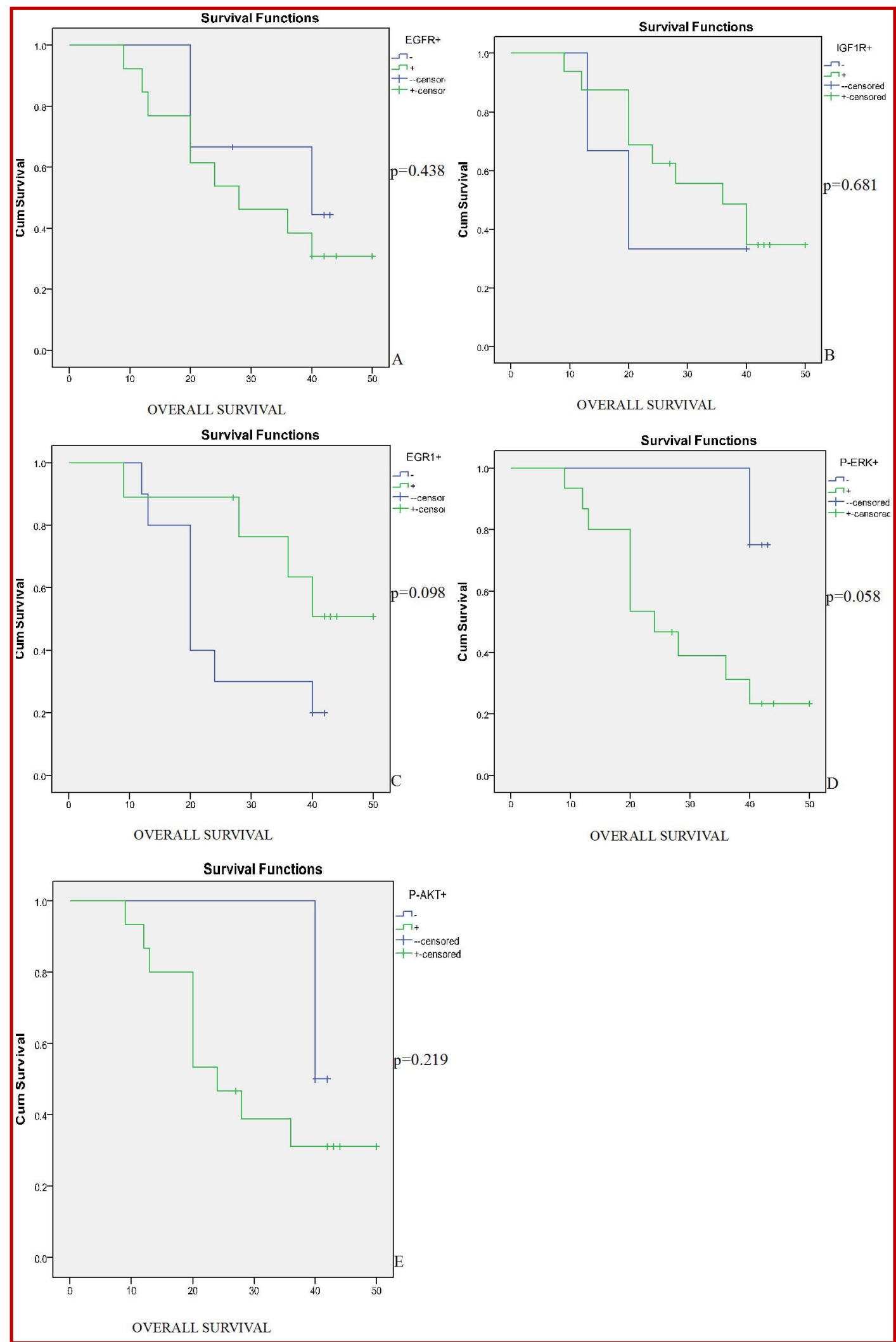

Figure 3: Survival analysis of lung cancer biomarkers in NSCLC

Note: Kaplain-Meier test and log-rank test was used to evaluate how the NSCLC survival was impacted by the overexpression of biomarkers EGR1, EGFR and IGF1R in tumor tissues, or the overexpression of pErk and pAkt in paracancer tissues 
EGFR protein expression was correlated with the pathological subtype, pathological stage and smoking history, but was not correlated with survival. Study has found that both EGFR gene copy number and its protein expression are over expression in NSCLC, and there is apparent correlation between them (Hirsch et al., 2003). In NSCLC patients, EGFR overexpression is related with fast metastasis, short disease free survival, high relapse rate, poor survival and lower chemoradiation sensitivity (Ohsaki et al., 2000). These suggest that EGFR plays a biological role in NSCLC, affects deterioration, progression, lymph node metastasis and malignant proliferation, and may be involved in NSCLC pathogenesis.

In the present study, IGF1R protein overexpression was detected in above $60 \%$ NSCLC tissues. In NSCLC, the IGF1R protein expression was correlated with the pathological subtype (Table III), not correlated with survival. High IGF1R gene copy number and protein overexpression are common in NSCLC, particularly in SCCs (Tran et al., 2014). The IGF1R signaling mechanism has been found to be associated with the resistance to a variety of anti-tumor therapies including EGFR inhibitors and cisplatin (LeRoith and Jr Roberts, 2003; Riedemann and Macaulay, 2006; CortésSempere et al., 2013), acting as a potentially predictor for resistance to gefitinib in NSCLC patients (Peled et al., 2013; Chen et al., 2013). Although studies have presumed that IGF1R overexpression is related with tumor replace and poor disease-free survival, other studies consider it not to be prognostically relevant, and the clinical significance of IGF1R expression in NSCLC is not confirmed (Nakagawa et al., 2012; Kimet al., 2014; Kimet al., 2012). Study has reported that the IGF1R expression status is not correlated with either tumor pathological status, differentiation and history of smoking, or smoking index. Better sensitivities of chemotherapy are detected in patients with IGF1R negative (Ning et al., 2010). Patients with concomitant IGF1R/EGFR FISH+/IHC+ have poor disease-free survival and poor overall survival $(p=0.005$ and $p=$ 0.01, respectively) (Ludovini et al., 2013). IGF1R expression is associated with the smoking history, squamouscelled carcinoma histology, K-Ras mutations, wild-type EGFR and hyporesponsivenes to EGFR tyrosine kinase inhibitors (Kim et al., 2012). These suggest IGF1R play some biological role in NSCLC, and may be involved in NSCLC pathogenesis.

In the present study, EGR1 protein overexpression was detected in more than $60 \%$ NSCLC tissues. In NSCLC, EGR1 protein expression was correlated with differentiation, pathological subtype and smoking history, but not associated with survival. These results suggested that EGR1 played biological roles in NSCLC, affected malignant transformation, malignant proliferation, and may be involved in NSCLC pathogenesis $(0.05<\mathrm{p}<0.1)$.
Dergunoa et al. have indicated that EGR1 gene expression is lower in human lung cancer tissues compared with normal tissues, presuming that EGR1 is an tumor suppressor gene in lung cancer (Dergunoa et al., 2007). Ferraro et al. have reported that EGR1 gene expression is not associated with clinical stage or pathological subtype, but is associated with survival (Ferraro et al., 2005). EGR1 is overexpressed in the KRAS or EGFR-mutated adenocarcinoma cells (Neufeld et al., 1999). EGR1 is inhibited in gefitinib-resistant NSCLC following PTEN down-regulation (Neufeld et al., 1999). The results regarding EGR1 in the present study prompted us to question whether EGR1 was only an anti-oncogene of NSCLC. EGR1 may have different function in NSCLC, through different mechanisms or signaling cross talk. Thus, further study is needed for exploring the EGR1 related molecule mechanism in NSCLC.

In the present study, pErk protein overexpression was detected in more than $60 \%$ paracancer tissues. In NSCLC, pErk protein expression was correlated with differentiation, pathological subtype, pathological stage and smoking history, and might be inversely correlated with survival $(0.05<p<0.1)$. Study has reported that pErk is found mainly in the margins of tumor mass, invading normal tissues seemly; the staining for pErk is apparently related to neoplasm invasiveness (Hoshino et al., 1999; Vicent et al., 2004). Intracytoplasm staining for pErk is related to poor prognosis, but not an independent prognosis factor. These suggest pErk plays roles in NSCLC differentiation, development and local infiltration.

In the present study, pAkt protein overexpression was detected in more than $50 \%$ paracancer tissues. pAkt protein expression was correlated with differention, pathological subtype, pathological stage and smoking history in NSCLC, and was not correlated with survival. Study has found that $23-67 \%$ NSCLC specimens exhibit a pAkt staining positive by immunostaining assay (Hirami et al., 2014). pAkt is also found mainly in the margins of tumor mass, invading normal tissues seemly (Neufeld et al., 1999). These suggest pAkt involves in NSCLC differentiation, development and local infiltration.

Both the RAS/RAF/MAK/ERK pathway and the $\mathrm{PI} 3 \mathrm{~K} / \mathrm{AKT} / \mathrm{mTOR}$ pathway play important roles in NSCLC tumorigenesis. Not only EGFR but also IGF1R affect NSCLC tumorigenesis via the above two pathways. In the present study, more than $60 \%$ tumor tissues overexpressed EGFR and IGF1R in NSCLC, and paracancer tissues overexpressed pErk and pAkt. Correlation analysis indicated that EGFR and IGF1R interacted with each other to produce a markedly effect on NSCLC via the ERK pathway and AKT pathway, by turn activated the EGR1 expression, thus they were involved in NSCLC tumorigenesis and development. 
There was correlation between the ERK pathway and the AKT pathway.

Study has reported that IGF1R interferes with the EGFR TKI activity (Vazquez-Martin et al., 2013; Morgillo et al., 2006). Hypoxia activates IGF1R, further increasing the population of lung cancer stem cells, which is resistant to gefitinib in EGFR mutation-positive NSCLC (Murakami et al., 2014). By inhibiting IGF1R synthesis, NSCLC cells' drug resistance to EGFR TKI is eliminated, resulting in tumor cell apoptosis in vivo and in vitro (Morgillo et al., 2006). Followed by the downstream Src-Mek-Erk signal transduction cascade reaction, ionizing radiation activates IGF1R, resulting in the transactivation of EGR1 (Morgillo et al., 2006). Various extracellular signal factors including cell growth factor, insulin and tissue factor can induce EGR1 gene expression (Revest et al., 2005). Erk protein kinase, belonging to MAP protein kinase family, is a most important upstream signal kinase, which induces EGR1 expression (McNeil et al., 2005). Not only pEGFR but also pAkt play important roles in EGR1 overexpression (Kaufmann et al., 2002). Through EGR1 and/or Erk1/2, wild-type EGFR can sustain cell viability in lung adenocarcinoma (Neufeld et al., 1999). EGR1 transcription factor is inhibited in EGFR-TKI resistant lung adenocarcinoma (Neufeld et al., 1999).

\section{Conclusion}

The levels of EGR1, EGFR and IGF1R expression were correlated with the activation of the ERK and AKT signaling pathways, suggesting some role of these factors in the downstream activation. EGR1 and pErk expression might be associated with survival, thus they might be potential predictors for NSCLC prognosis.

\section{Conflict of Interest}

There are no conflicting interests.

\section{References}

Chen B, Xiao F, Li B. The role of epithelial-mesenchymal transition and IGF-1R expression in prediction of gefitinib activity as the second-line treatment for advanced non-small -cell lung cancer. Cancer Invest. 2013; 31: 454-60.

Cortés-Sempere M, de Miguel MP, Pernía O. IGFBP-3 methylation-derived deficiency mediates the resistance to cisplatin though the activation of the IGFIR/Akt pathway in nonsmall cell lung cancer. Oncogene 2013; 32: 1274-83.

Dergunoa LV, Raevskaia NM, Volosheniuk EL, Limborskaia SA. Expression peculiarities of EGR1, neurotrophins and their receptor genes in human lung cancer and in normal lung tissue. Mol Gen Mikrobiol Virusol. 2007; 2: 25-30.
Ferraro B, Bepler G, Sharma S, et al. EGR1 predicts PTEN and survival in patients with non-small-cell lung cancer. J Clin Oncol. 2005; 23: 1921-26.

Hirami Y, Aoe M, Tsukuda K, et al. Relation of epidermal growth factor receptor, phosphorylated-Akt, and hypoxiainducible factor-1 alpha in non-small cell lung cancers. Cancer Lett. 2004; 214: 157-64.

Hirsch FR, Varella-Garcia M, Bunn PA Jr, et al. Epidermal growth factor receptor in non-small-cell lung carcinomas: Correlation between gene copy number and protein expression and impact on prognosis. J Clinic Oncol. 2003; 21: 3798-807.

Hoshino R, Chatani Y, Yamori T, et al. Constitutive activation of the 41-/43-kDa mitogen-activated protein kinase signaling pathway in human tumors. Oncogene 1999; 18: 813-22.

Kaufmann K, Thiel G. Epidermal growth fact or and thrombin induced proliferation of immortalized human keratinocyt es is coupled to the synthesis of Egr-1, a zinc finger transcriptional regulator. J Cell Biochem. 2002; 85: 381-91.

Kim JS, Kim ES, Liu D, Nakagawa M, Uramoto H, Oka S, et al Clinical significance of IGF1R expression in non-small-cell lung cancer. Clin Lung Cancer. 2012; 13: 136-42.

Kim JS, Kim ES, Liu D, et al. Prognostic impact of insulin receptor expression on survival of patients with non-small cell lung cancer. Cancer. 2012; 118: 2454-65.

Kim WY, Prudkin L, Feng L, et al. Epidermal growth factor receptor and K-Ras mutations and resistance of lung cancer to insulin-like growth factor1 receptor tyrosine kinase inhibitors. Cancer. 2012; 118: 3993-4003.

LeRoith D, Roberts CT Jr. The insulin-like growth factor system and cancer. Cancer Lett 2003; 195: 127-37.

Ludovini V, Flacco A, Bianconi F, et al., Concomitant high gene copy number and protein overexpression of IGF1R and EGFR negatively affect disease-free survival of surgically resected non-small-cell-lung cancer patients. Cancer Chemother Pharmacol. 2013; 71: 671-80.

McNeil LK, Starr TK, Hogquist KA. A requirement for sustained ERK signaling during thymocyte posit ive select ion in vivo. Proc Natl Acad Sci USA. 2005; 102: 13574-79.

Morgillo F, Woo JK, Kim ES, et al. Heterodimerization of insulin-like growth factor receptor/epidermal growth factor receptor and induction of survivin expression counteract the antitumor action of erlotinib. Cancer Res. 2006; 66: 10100-11.

Mukohara T, Kudoh S, Yamauchi S, et al., Expression of epidermal growth factor receptor (EGFR) and downstreamactivated peptides in surgically excised non-small-cell lung cancer (NSCLC). Lung Cancer. 2003; 41: 123-30.

Murakami A, Takahashi F, Nurwidya F. Hypoxia increases gefitinib-resistant lung cancer stem cells through the activation of insulin-like growth factor 1 receptor. PLoS One. 2014; 9: e86459.

Nakagawa M, Uramoto H, Oka S, et al., Clinical significance of IGF1R expression in non-small-cell lung cancer. Clin Lung Cancer. 2012; 13: 136-42.

Neufeld G, Cohen T, Gengrinovitch S, Poltorak Z. Vascular 
endothelial growth factor (VEGF) and its receptors. FASEB J. 1999; 13: 9-22.

Ning $\mathrm{XH}$, Wang $\mathrm{YZ}$, Bai $\mathrm{CM}$, et al. Clinical significance of insulin-like growth factor-1 receptor in platinum-based chemotherapy for non-small cell lung cancer. Zhongguo Yi Xue Ke Xue Yuan Xue Bao. 2010; 32: 366-70.

Ohsaki Y, Tanno S, Fujita Y et al. Epidermal growth factor receptor expression correlates with poor prognosis in nonsmall cell lung cancer patients with p53 overexpression. Oncol Rep. 2000; 7: 603-07.

Peled N, Wynes MW, Ikeda N. Insulin-like growth factor-1 receptor (IGF-1R) as a biomarker for resistance to the tyrosine kinase inhibitor gefitinib in non-small cell lung cancer. Cell Oncol (Dordr). 2013; 36: 277-88.

Revest JM, Di Blasi F, Kitchener P, et al. The MAPK pathway and Egr-1 mediate stress-related behavioral effects of glucocorticoids. Nat Neurosci. 2005; 8: 664-72.

Riedemann J, Macaulay VM. IGF1R signalling and its inhibition. Endocr Relat Cancer. 2006; 13(Suppl 1): S33-S43.

Tran TN, Selinger CI, Yu B. Alterations of insulin-like growth factor-1 receptor gene copy number and protein expression are common in non-small cell lung cancer. J Clin Pathol. 2014.

Vazquez-Martin A, Cufí S, Oliveras-Ferraros C. IGF-1R/ epithelial-to-mesenchymal transition (EMT) crosstalk suppresses the erlotinib-sensitizing effect of EGFR exon 19 deletion mutations. Sci Rep. 2013; 3: 2560.

Vicent S, Lopez-Picazo JM, Toledo G, et al. ERK1/2 is activated in non-small-cell lung cancer and associated with advanced tumours. Bri J Cancer. 2004; 90, 1047-52. 


\section{Your feedback about this paper}

1. Number of times you have read this paper 0

2. Quality of paper
Excellent
Good
Moderate
Not good

3. Your comments

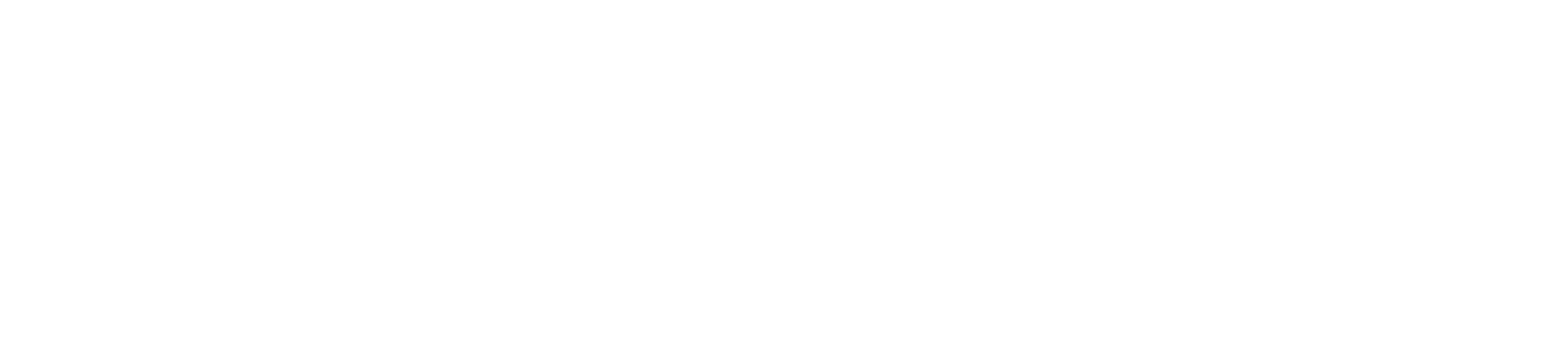

